\title{
An agent-based integrated model of recreational fishing and coral reef ecosystem dynamics for site closure strategy analysis
}

\author{
$\underline{\text { L. Gao }}^{\text {a }}$ and Atakelty Hailu ${ }^{\text {b }}$ \\ ${ }^{a}$ CSIRO Land and Water, PMB 2, Glen Osmond, Adelaide, South Australia 5064, Australia \\ ${ }^{b}$ School of Agricultural and Resource Economics, University of Western Australia, 35 Stirling Highway, \\ Perth, Western Australia 6009, Australia \\ Email addresses: dr.leigao@gmail.com and atakelty.hailu@uwa.edu.au
}

\begin{abstract}
Managing recreational fishing is among the most difficult natural resource management problems. The complex nature of the impacts caused by management changes makes it difficult to identify the full range of ecological and socio-economic effects. It is difficult to distinguish approaches that are effective from those that are not. For example, the evaluation of area closure strategies needs to incorporate the relationships among stock dynamics, angler responses and consequent changes in the geographical distribution of fishing efforts. Empirically-based tools are needed to predict responses to, and outcomes from, management decision that affect fish stocks and fishing benefits.

To address this, an integrated agent-based simulation model of recreational fishing and a coral reef system is presented in this paper to evaluate ecological and economic impacts. Angler behaviour is driven by empirically estimated site choice models which link recreational choices to site attributes and angler characteristics. Coral reef ecosystem dynamics is modelled using a local-scale model describing the relationship between fish populations, fishing activities as well as algal and coral cover.

We apply the model to the evaluation of area closure strategies. As a case study for this paper, we choose recreational fishing sites from the Ningaloo Marine Park, an iconic coral reef system in Western Australia. The results show that not only the effectiveness but also the distribution of management impacts can be very different from what one would expect without the benefit of integrated modelling. The simulation of a management change on site closure demonstrates the extent to which the often controversial subjects of recreational fishing management can be facilitated using predictive modelling.
\end{abstract}

Keywords: recreational fishing, strategy evaluation, integrated ecological-economic modelling, agent-based model, area closure, random utility models 
Gao and Hailu, An agent-based integrated model for strategy analysis of recreational fishing

\section{INTRODUCTION}

Recreational fishing is a highly controversial subject. This is because the complexity of the impacts caused by management changes makes it difficult to identify the full range of ecological and socio-economic impacts and to distinguish approaches that are effective from those that are not. In recent years, there has been growing concerns about the sustainability and management of recreational fisheries as well as the conservation of fish stocks subjected to recreational fishing. In addition, recreational fishing brings substantial social and economic benefits that are not reflected in market transactions. Therefore, resource managers need to weigh carefully the trade-offs involved in the management of recreational fishing. In particular, a careful balance needs to be struck between providing opportunities to enrich the experience of recreationists (and hence the economic value of recreational fishing), on the one hand, and minimizing impacts on the natural environment and fish stocks, on the other.

Fishery area closure is popular as a conservation management tool aimed at limiting fishing efforts and maximizing yields (Little et al., 2009). The area closures can help achieve broad fishery and biodiversity objectives, but their use requires careful planning and evaluation. The evaluation of area closure strategies needs to incorporate the relationships among stock dynamics, angler responses and consequential impacts on the geographical distribution of fishing activities.

This paper presents an integrated agent-based simulation (ABS) model that combines a recreational fishing site choice model and an ecological model of a coral reef environment. An ABS model is a bottom-up approach that abstracts a complex system as a collection of interacting, autonomous agents. In our model, recreational anglers and fishing sites are all modeled as agents. The behaviour of angler agents is represented by empirically based Random Utility Models (RUMs) (McFadden, 1974) that rationalize choices on the basis of attributes of the individuals, the features of alternative sites and recreational experience. A coral reef ecosystem model is used to simulate the interactions among algae, corals, herbivorous and piscivorous fish. The integrated model makes it possible to undertake "what-if" scenario analyses and allows researchers and managers to better understand the wide range of economic and environmental implications of management strategies.

The work presented in this paper improves on results reported in (Gao and Hailu, 2011) in the following two ways: (1) the RUM is empirically estimated using data from a survey in the Ningaloo Marine Park of Western Australia, rather than the national survey of recreational fishers (Henry and Lyle, 2003); and (2) a new coral reef ecosystem model is adopted to more accurately depict the interactions among different trophic levels in a coral reef ecosystem. The rest of the paper is organized as follows. The next section describes the structure of the integrated ABS model. Section 3 presents the results from a case study which focuses on the evaluation of a site closure management strategy in the Ningaloo Marine Park. Section 4 summarizes and concludes the paper.

\section{AN INTEGRATED ABS MODEL OF RECREATIONAL FISHING}

The ABS model combines a host of econometric models with a trophic-dynamic model of a coral reef ecosystem. A schematic diagram of the major components is presented in Figure 1. A recreational angler has demographic attributes (such as age, income, and education level) and behaviors (such as choosing sites and catching fish). These behaviours are structured using empirically estimated econometric models. A fishing site has environmental attributes (such as coral cover, algal cover, herbivorous fish biomass, piscivorous fish biomass, area, and coastal length) and ecological activities (interactions among the environmental attributes). 


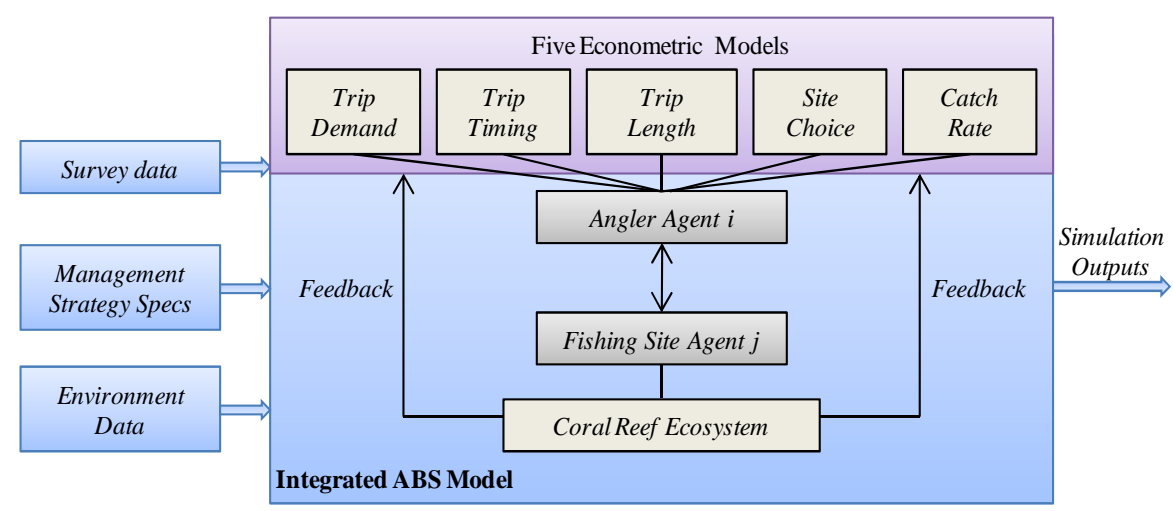

Figure 1. Schematic diagram of the integrated ABS model components.

Five econometric models (trip demand model, trip timing model, trip length model, site choice model, and catch rate model) underpin the decision-making process on which a recreational angler's behaviour is structured. These models predict, respectively, the number of recreational trips taken in a year, the timing of a trip in a year, the length or duration of a trip, the choice of recreational site in any one trip, and the agent's expected fish catch for any given site. The coral reef ecosystem model describes interactions among four components in a coral reef environment, namely, algal growth, coral cover, herbivore fish and piscivore fish. Below we describe in more detail the models that constitute the simulation platform.

\subsection{Recreational behaviour models}

The trip demand model predicts the actual number of trips taken by angler (in a year) as a Poisson distribution. The logarithm of the number of trips in the Poisson model $\left(\lambda_{i}\right)$ is specified as equation (1).

$$
\ln \lambda_{i}=\beta_{0}+\beta_{1} \cdot I V_{i}+\sum_{m} \beta_{m} y_{m}
$$

where $y_{m}$ represents $m$-th individual characteristic (such as age or education). The $I V_{i}$ variable, as a measure of the expected maximum utility from a set of choices, is routinely used to valuate environmental changes in the non-market literature (McFadden, 1974). It is calculated from site utility values as shown in equation (2).

$$
I V_{i}=\ln \sum_{j=1}^{M} e^{U_{i j}}+0.5772
$$

where $U_{i j}$ (also see equation (4)) is the utility that angler agent $i$ derives from recreational fishing at a recreational angling site $\mathrm{j}$ out of $\mathrm{M}$ sites. The variables and coefficient estimates in the trip demand model are presented in Raguragavan et al. (2010).

The trip timing decision is a discrete choice problem, with the choices being the days in the year when an angler starts their fishing trip(s). We used the timing information in the survey data to estimate a logit model for trip timing and this model is used in the agent-based model to determine trip start dates. Trip length on the other hand is a continuous variable that takes a value of 1 or higher. We estimated a limited dependent variable model, Tobit, to provide a means of predicting fishing holiday lengths. The variables and coefficient estimates of the two models are presented in Table 3 and Table 4 in Hailu and Gao (2012), respectively.

A RUM is used to predict angler preferences among a set of alternative sites. Fishing site choice is driven by cost of visit to the site, expected catch rates, the isolation score of the site, as well as other recreational attributes of the site. The most common RUM formulation is the multinomial logit (McFadden, 1974), which 
provides the following closed form for the expression of the probability ( $\left.p r o b_{i j}\right)$ that a person $i$ chooses site $j$ from $M$ sites depending on the utilities expected from each of those sites.

$$
\operatorname{prob}_{i j}=e^{U_{i j}} / \sum_{k=1}^{M} e^{U_{i k}}
$$

where, $U_{i j}$ is the utility that angler $i$ derives from fishing at site $j$ and is dependent on site and angler characteristics as shown in equation (4).

$$
U_{i j}=\beta_{j}+\beta_{c} \cdot \operatorname{cost}_{i j}+\sum_{f} \beta_{f} \cdot C R_{i j f}+\sum_{k} \beta_{k} \cdot S_{k j}
$$

where, $\beta_{j}$ is the base utility of a site, $\operatorname{cost}_{i j}$ is the cost to $i$ of recreating at site $j, C R_{i j f}$ represents the number of fish of type $f$ that the individual expects to catch at the site, and $S_{k j}$ stands for other site attributes that affect choice. The estimation results for the model used here are presented in Table 9 in Hailu et al. (2011). The expected catch rates in the model depend on fish stocks and the angler's experience. These rates are generated by another econometric model, the catch rate model, shown below in equation (5).

$$
\ln \lambda_{i j f}=\beta_{0}+\beta_{1} \cdot \text { stock }_{j f}+\beta \cdot S
$$

where, $\lambda_{i j f}$ is the expected catch per trip of angler agent $i$ at site $j$ for fish type $f$; stock $k_{j f}$ is the annual total stock at site $j$ of fish type $f ; S$ is a vector of attributes (such as whether the fishing site is man-made) for fishing site $j$ and a set of angler demographic variables that influence expected catch. The catch rate functions used in our study are based on those reported in Table A5 in Raguragavan et al. (2010).

We refer readers to (Gao and Hailu, 2011, Hailu and Gao, 2012, Raguragavan et al., 2010) for detailed model specifications and discussion of estimates.

\subsection{Coral reef ecosystem model}

To describe interactions among algae, corals, and fish at a site, the coral reef ecosystem model uses a localscale model of trophic dynamics (Fung, 2009). This model was originally developed as ordinary differential equations (ODEs) which have been parameterized for reefs in the Indo-Pacific region and the Western Atlantic region. Equilibrium behaviour and parameter sensitivity of the model have been examined in detail (Fung, 2009). Since the coral reef ecosystem targeted (Ningaloo reefs) has insignificant amounts of turf algae and sea urchins, this model has been simplified with only five functional groups, namely, hard corals $(C)$, macroalgae $(A)$, grazed epilithic algal community or EAC $(E=1-C-A)$, herbivorous fish $(H)$, and piscivorous fish $(P)$. The ODEs describing the proportional covers of hard corals, algae (macroalgae), EAC, herbivorous fishes, and piscivorous fishes, are shown in equations (6)-(10).

$$
\begin{gathered}
\frac{d C}{d t}=\left(l_{C}^{S}+l_{C}^{b} \cdot C\right) \cdot E+r_{C} \cdot\left(1-\beta_{A} \cdot A\right) \cdot E \cdot C-d_{C} \cdot C-\gamma_{A C} \cdot r_{A} \cdot A \cdot C \\
\frac{d A}{d t}=r_{A} \cdot A \cdot\left(E+\gamma_{A C} \cdot C\right)-g_{A} \cdot \theta_{H} \cdot A \\
\frac{d E}{d t}=-\frac{d C}{d t}-\frac{d A}{d t} \\
\frac{d H}{d t}=l_{H}^{e x}+l_{H}^{e n} \cdot H+\theta_{H} \cdot g_{A} \cdot A \cdot \mu_{A}-d_{H} \cdot H-g_{P} \cdot \frac{H^{2}}{i_{P H}^{2}+H^{2}} \cdot P-f_{H} \\
\frac{d P}{d t}=l_{P}^{e x}+l_{P}^{e n} \cdot P+r_{P} \cdot g_{P} \cdot \frac{H^{2}}{i_{P H}^{2}+H^{2}} \cdot P-d_{P} \cdot P-\psi_{P} \cdot g_{P} \cdot\left(1-r_{P}\right) \cdot \frac{P^{2}}{i_{P P}^{2}+P^{2}} \cdot P-f_{P}
\end{gathered}
$$

Since difference equations are most appropriate when organisms have discrete, non-overlapping generations, our coral reef ecosystem model converts the above differential into difference equations using Euler's method. Further, in the version used here the fish harvest prediction differs from Fung's in that our harvest predictions are based on the RUM and fish catch rate models. 


\section{A CASE STUDY}

In this study, we model fishing in eleven sites within the Ningaloo Marine Park of Western Australia. Situated on the North West Cape of Western Australia, Ningaloo Reef supports a wide diversity of marine species that attract recreational tourism. Reef fish are very popular among anglers. A map of the Ningaloo sites is shown in Figure 2.

Eleven fishing sites (Learmonth, Exmouth, Bundegi, North West Reef, Lighthouse Bay, Tantabiddi, Ned's Camp, Pilgramunna, Yardie Creek, Coral Bay, Warroora) located in this area are included in our model. Below we report results from a simulation of recreational angling activities and coral reef system dynamics for a period of 20 years, from 2011 to 2030. First, we have a baseline (business as usual) strategy where there is no management change. Then we evaluate a site closure strategy: the number of accessible sites is taken from 11 to 10 with Tantabiddi closing in 2015. The reason we close this site is because it is the most popular destination

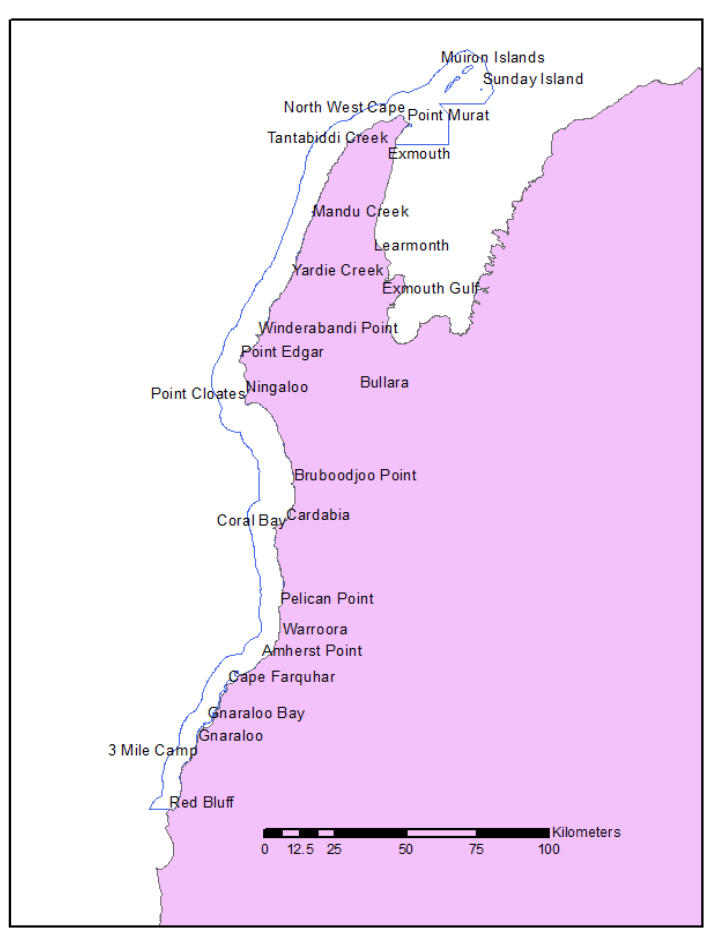

Figure 2. The map of Ningaloo sites. in our simulation of the baseline scenario.

Figure 3 demonstrates the percentages of total visits for each fishing destination per year before and after carrying out a site closure scenario. In the baseline scenario, Tantabiddi has the largest number of visits among the eleven sites. By comparing the total number of fishing visits to all sites before and after the closure of Tantabiddi, we find that the average numbers of trips across the eleven sites combined remain stable, confirming that fishing efforts are being redistributed rather than reduced as result of the closure. The fishing efforts from Tantabiddi are redistributed to Learmonth, Exmouth, Bundegi, North West Reef, Lighthouse Bay, Ned's Camp, Pilgramunna, and Yardie Creek. This is because travel distance is an important

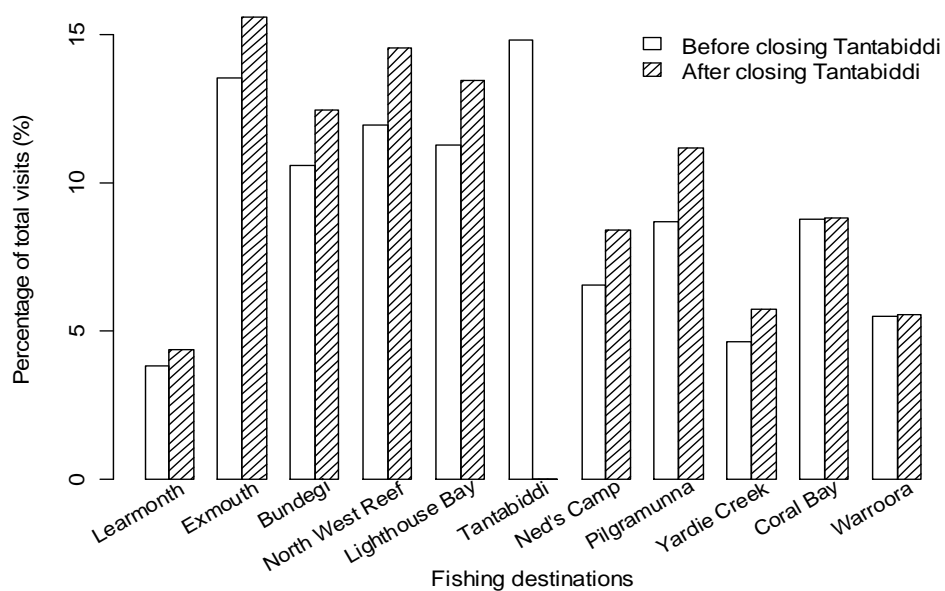

Figure 3. Fishing visits at all destinations before and after Tantabiddi closure. factor affecting site choice. The alternative sites are at a distance of less than 75 kilometres from to the closed site, Tantabiddi, which is about 193 and 260 kilometers from Coral Bay and Warroora, respectively.

The comparisons in algal cover, coral cover, herbivorous fish biomass, and piscivorous fish biomass between two scenarios are shown in Figures 4(a)-(d), respectively. Such a comparison is measured as a ratio of a trophic variable value in the site closure scenario to the corresponding value in the baseline scenario. The ratio is represented as equation (11). 
Gao and Hailu, An agent-based integrated model for strategy analysis of recreational fishing

$$
r_{y}^{t}=i n d_{-} c_{y}^{t} / \text { ind_ } b_{y}^{t}
$$

where $r_{y}^{t}$ is the ratio of a trophic level $t$ in year $y, i n d_{-} c_{y}^{t}$ is the value of a trophic level $t$ in year $y$ under the site closure scenario, and $i n d \_b_{y}^{t}$ is the value of a trophic level $t$ in year $y$ under the baseline scenario.
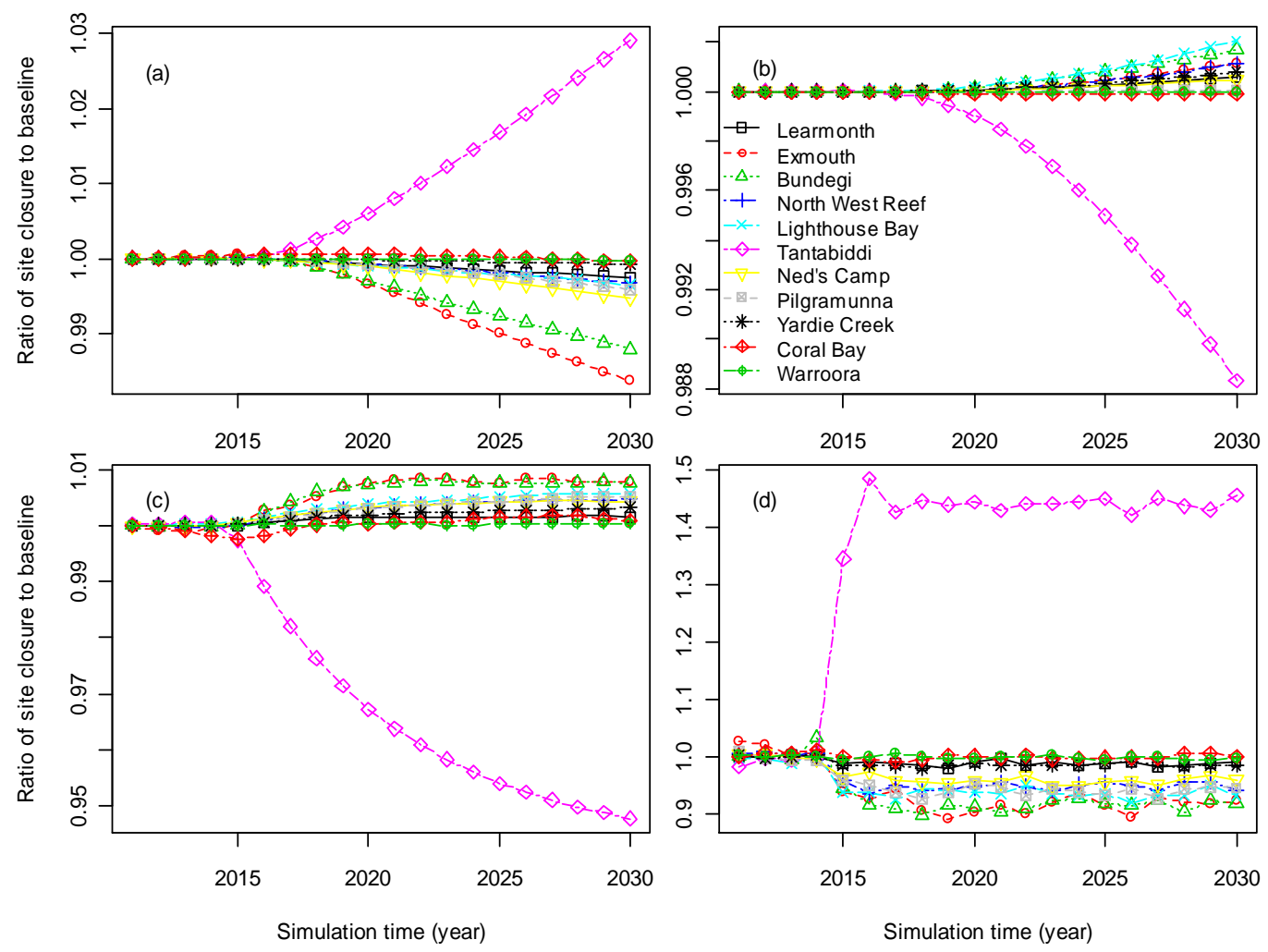

Figure 4. The ratios of site closure to baseline scenario values for four trophic outcomes: (a) algal cover, (b) coral cover, (c) herbivorous fish biomass, and (d) piscivorous fish biomass.

The target fish species for the area are mainly piscivorous. The dynamic change in piscivorous fish biomass in different sites provides an indication of the effects on fish stock and is shown in Figure 4(d). This biomass increases rapidly for Tantabiddi after the site closure in 2015, then levels off at about $9400 \mathrm{~kg} / \mathrm{km}^{2}$, which is about 1.45 times the level in the initial four years. However, the redistribution of fishing efforts to open sites means that the other sites have to accommodate more fishing harvests, resulting in lowered biomass levels. The dynamics of herbivorous fish biomass and coral cover are opposite to that of the piscivorous fish biomass (see Figure 4(b) and (c)). Rises in piscivorous fish populations lead to lower herbivore populations, which lead to higher algal but lower coral covers. For the open sites, this means that coral covers improve.

The economic benefit values that are central to informed decision making are the economic surplus measures which reflect the value of the fishing experience changes to anglers. The RUM approach used in this paper can construct welfare estimates at the individual level (i.e. for each angler), allowing resource managers to assess the impacts of management change on different segments of society. Further, these welfare estimates can be aggregated up to the population level for use in cost-benefit analysis and the evaluation of changes in recreational management. The economic surplus measure described in (Gao and Hailu, 2011) is used to reflect the value of anglers' fishing experience. The measurement result shows the closure of a site reduces 
Gao and Hailu, An agent-based integrated model for strategy analysis of recreational fishing

angler economic welfare by about $12 \%$ on the aggregate. In decision making, this welfare loss needs to be compared with piscivorious fish biomass change. In this particular case, the piscivorious fish biomass across all fishing sites increases after the closure because the gain in fish biomass in the closed site is much greater than the losses across all the open sites.

\section{CONCLUSIONS}

This paper has provided the structure of an integrated model for simulating recreational fishing and ecosystem dynamics in a coral reef environment. The value of models that allow resource managers to evaluate both ecological impacts and the welfare of proposed or potential changes in management cannot be overstated. The models provide non-market value estimates for recreational fishing which are rarely available to decision makers and these values can be compared against other changes (losses or gains) in environmental outcomes to make more informed decisions. A simulation of recreational fishing activities and their interactions with recreational environment in Ningaloo Marine Park is conducted with the purpose of illustrating the value of integrated modelling in assessing different area closure strategies. The results show how, with the benefit of an integrated model, our capacity for assessing the effectiveness and implications (including spill-over effects) of management strategies can be greatly improved.

\section{ACKNOWLEDGMENT}

This work was supported by the Ningaloo Collaboration Cluster, CSIRO Wealth from Oceans Flagship Program. The authors gratefully acknowledge the contribution of Tak Fung, who provided advice during the modification and calibration of the coral reef ecosystem model presented in this paper. The authors are grateful to Jeff Durkin for research work on the survey data.

\section{REFERENCES}

Fung, T. C. (2009). Local scale models of coral reef ecosystems for scenario testing and decision support. London, United Kingdom, University College London.

Gao, L. and Hailu, A. (2011). Evaluating the effects of area closure for recreational fishing in a coral reef ecosystem: The benefits of an integrated economic and biophysical modelling. Ecological Economics, $70(10), 1735-1745$

Hailu, A. and Gao, L. (2012). Recreational trip timing and duration prediction. Tourism Economics, In press. Also available online at: AgEcon Search (http://ageconsearch.umn.edu/handle/97474).

Hailu, A., Gao, L., Durkin, J. and Burton, M. (2011). Estimation and integration of socioeconomic values of human use of Ningaloo. Ningaloo Collaboration Cluster Final Report No. 4.

Henry, G. W. and Lyle, J. M. (2003). The National Recreational and Indigenous Fishing Survey, Canberra, Australia, Australian Government Department of Agriculture, Fisheries and Forestry.

Little, L. R., Punt, A. E., Mapstone, B. D., Begg, G. A., Goldman, B. and Ellis, N. (2009). Different responses to area closures and effort controls for sedentary and migratory harvested species in a multispecies coral reef linefishery. ICES Journal of Marine Science, 66(9), 1931-1941.

Mcfadden, D. (1974). The measurement of urban travel demand. J. Public Economics, 3(4), 303-328.

Raguragavan, J., Hailu, A. and Burton, M. (2010). Economic valuation of recreational fishing in Western Australia. Working Paper 1001, School of Agricultural and Resource Economics, University of Western Australia, Crawley, Australia. Available online at: AgEcon Search (http://ageconsearch.umn.edu/handle/97473). 